\title{
Galceran x Piñeyro: una transposición del teatro al cine
}

\author{
Alfredo Dillon ${ }^{1}$ \\ Universidad Católica Argentina
}

\section{Resumen}

El artículo propone un estudio comparado de la obra teatral El método Grönholm, del dramaturgo catalán Jordi Galceran, con su transposición cinematográfica: El método (2006), del director argentino Marcelo Piñeyro. Se analizan los procedimientos de transformación de la configuración espacial, la construcción de los personajes, los desplazamientos genéricos y el desenlace. También se abordan los modos de vinculación que cada texto establece con su respectivo contexto histórico y se problematiza el tratamiento alegórico de las relaciones sociales bajo el neoliberalismo.

\section{Palabras clave}

Adaptación, transposición, cine argentino, teatro, El método

\begin{abstract}
This article offers a comparative study of The Grönholm Method, a play by the Catalan playwright Jordi Galceran, and The Method (2006), its cinematographic adaptation, directed by Marcelo Piñeyro. We analyze the transformations of spatial configuration, the construction of characters, the shifts in genre and the different endings. We also study the ways in which each text relates to its historical context, and we discuss the allegorical treatment of social relations under neoliberalism.
\end{abstract}

\section{Keywords}

Adaptation, transposition, Argentine cinema, drama, The Method

\footnotetext{
${ }^{1}$ Alfredo Dillon es investigador del Instituto de Investigaciones de la Facultad de Ciencias Sociales de la Universidad Católica Argentina. Actualmente cursa el doctorado en Ciencias Sociales de la Universidad de Buenos Aires y es licenciado y profesor en Letras (UBA). Sus publicaciones académicas más recientes son sobre cine argentino contemporáneo. Desde 2006 es docente en la UCA.
} 


\section{Introducción}

El análisis de la interdiscursividad teatro/cine, inscripto en el campo de la Comparatística, permite dar cuenta de las afinidades y las tensiones entre dos lenguajes artísticos heterogéneos. En ese sentido, el objetivo de este artículo es estudiar la transposición cinematográfica de la película argentino-española El método (2006), de Marcelo Piñeiro, basada en la obra teatral El método Grönholm, del dramaturgo catalán Jordi Galceran.

Por tratarse de una transposición del teatro al cine, el análisis exige entablar un diálogo entre el lenguaje cinematográfico y un sistema semiótico en el que -siguiendo la clásica distinción aristotélica- la representación se rige por la acción de los personajes (el drama) y no por el relato de un narrador. Por otra parte, es una adaptación que ha sido rechazada por el autor del hipotexto: Galceran ha criticado la versión de Piñeyro por considerar que no se ajusta al original.

Resulta interesante analizar la adaptación de una obra teatral al cine, ya que, según autores como Bazin, esta operación presenta mayores dificultades que la transposición literaria: «Por lo menos la novela requiere un cierto margen de creación para pasar de la escritura a la imagen. El teatro, por el contrario, es un falso amigo; sus ilusorias semejanzas con el cine llevan a este a una vía muerta» (2008: 103). La adaptación cinematográfica de una obra teatral presentaría, entonces, un riesgo más alto de que el resultado sea fallido, apenas «teatro filmado», lo que -como el propio Bazin señalaconstituye una fórmula cristalizada para describir una mala película.

El método fue una coproducción entre Argentina, España e Italia, con la mayoría de los fondos $-\mathrm{y}$ del elenco- provenientes del segundo país. En escalas diferentes, tanto la obra como la película han logrado gran convocatoria de público. El método Grönholm se estrenó en 2003 en Barcelona, y al año siguiente la versión en castellano llegó a los teatros de Madrid. En 2005 tuvo su estreno en Buenos Aires, dirigida por Daniel Veronese en el Paseo La Plaza, donde permaneció en cartelera hasta 2007. Para ese momento, la pieza se había convertido en un éxito internacional: llegó a los teatros de 60 países (Perales, 2013).

El film, por su parte, estuvo entre las 10 películas argentinas más vistas de 2006, superando los 100.000 espectadores, aunque lejos de la primera, Bañeros 3, que tuvo 
más de un millón de espectadores. En España, donde se estrenó primero, el éxito fue mucho mayor: alcanzó los 460 mil espectadores. Entre otros premios, el film de Piñeyro ganó el Goya 2005 al Mejor guion adaptado. La transposición de la obra al cine estuvo a cargo del propio Piñeyro y de Mateo Gil, guionista habitual de Alejandro Amenábar -en Tesis (1995), Abre los ojos (1997), Mar adentro (2004) y Ágora (2009)-.

\section{El lugar de Piñeyro en el cine argentino}

Por el elenco -que reúne a varias estrellas del star system español-, por la locación transcurre en Madrid, aunque la ciudad prácticamente no se ve en la pantalla- y por el guion -con varias referencias al país ibérico-, la película resultó más atractiva para el público español que para el argentino. De todas maneras, por su director, por uno de sus protagonistas -Pablo Echarri- y por algunos de los temas que aborda, la película también se inscribe en el mapa del cine argentino.

Tras rechazar la versión cinematográfica, Galceran ha dicho en entrevistas que aspira a poder concretar una nueva adaptación cinematográfica de la obra teatral: «He recuperado los derechos para el cine de El método después de un pleito por ellos y espero que se pueda hacer algún día otra película» (Cabal, 2009: 345). Para el dramaturgo, el sentido de lograr una adaptación más fiel al original tiene que ver con la mayor permanencia de las películas, a diferencia de las obras teatrales, cuya disponibilidad para el receptor depende de que el texto sea llevado a escena: «Si adaptas una novela, la novela siempre está ahí, pero [...] la obra de teatro desaparece. La obra de teatro se estrena, tiene la vida que tiene, pero llega un momento que desaparece y queda la película» (cit. en Cabal, 2009). En otras palabras, a Galceran le preocupa que su creación quede «inmortalizada» en una versión a la que no considera representativa del original.

A diferencia del interés local e internacional suscitado por los directores aglutinados en el Nuevo Cine Argentino -Lucrecia Martel, Adrián Caetano, Pablo Trapero, Lisandro Alonso, Albertina Carri, Martín Rejtman y Daniel Burman, entre otros--, el cine de Marcelo Piñeyro casi no ha sido objeto de estudios académicos. Sus películas, como las de Juan José Campanella, no se ajustan a los parámetros estéticos ni de producción con que los críticos han caracterizado al Nuevo Cine, sino que dialogan más bien con las 
pautas estéticas y narrativas del cine hollywoodense. Cierto sector de la crítica lo ha definido como un «autor industrial» (Bernardes, Lerer, Wolf; 2002: 119), categoría que también podría aplicarse a Campanella o Damián Szifrón.

Como autor industrial, Piñeyro es un director de estilos cambiantes. Ha transitado el thriller, el drama y el policial; ha abordado distintas épocas históricas -si bien la diégesis de El método es estrictamente contemporánea a la filmación, la mayoría de sus películas transcurren en el pasado-, tanto en Argentina como en España, con presupuestos de superproducción o con condiciones más ajustadas. Sus películas tienden a privilegiar la palabra hablada por encima de la imagen, y suelen funcionar como alegorías. Los films de Piñeyro tienen mensaje: ese mensaje suele ser explícito, y queda a cargo de uno o varios personajes. Aun cuando la crítica los haya considerado poco innovadores en lo formal, su impacto en la audiencia los vuelve relevantes para el análisis.

El método (2006) fue la sexta película de Piñeyro como director, y la segunda adaptación: la primera había sido Plata quemada, basada en una novela de Ricardo Piglia, con gran éxito de público (aunque se la declaró prohibida para menores de 18 años, superó los 623.000 espectadores y fue una de las 5 películas argentinas más vistas del año 2000). Luego Piñeyro adaptó Las viudas de los jueves, el best seller de Claudia Piñeiro, y alcanzó con su versión cinematográfica 511.000 espectadores en 2009 (quedó detrás de El secreto de sus ojos en el ranking de taquilla del cine nacional).

Al igual que el resto de la filmografía de Piñeyro (con excepción de Caballos salvajes y Cenizas del paraíso), El método es una coproducción con España. En rigor, este rasgo es compartido con una porción significativa de las películas argentinas de los últimos 20 años, tras la creación del programa Ibermedia en 1998. Rubio Alcover anota que «mientras que en Plata quemada y en Kamchatka la participación mayoritaria corría a cargo de la parte argentina, en El método y Las viudas de los jueves las empresas españolas financiaron un porcentaje mayor de la operación» (2014: 137).

\section{Entre Darwin y Gran Hermano}

En El método, el guion de Piñeyro y Gil se queda con el tema y el planteo general de la obra de Galceran, pero descarta la mayor parte de los diálogos: los guionistas hicieron, 
en rigor, una versión libre, con un alto grado de autonomía respecto al original. El resultado se ajusta al que describe Sánchez Noriega al referirse a las adaptaciones libres: el espectador «puede reconocer la obra original, aunque haya transformaciones decisivas» (2000: 75).

La película conserva en buena medida la teatralidad de la obra original: hay ocho personajes encerrados en un mismo espacio, durante las dos horas de duración de largometraje (casi el doble que la obra original). En ese sentido, El método evoca a 12 hombres en pugna (1957), el clásico de Sidney Lumet en el que doce hombres debaten, encerrados en una habitación, sobre la inocencia o culpabilidad de un joven acusado de haber asesinado a su padre (la versión española se tituló 12 hombres sin piedad, nombre que la acerca aún más al film que nos ocupa).

En la película de Piñeyro -como en la de Lumet-, la acción se apoya casi únicamente en los diálogos. Las palabras que intercambian estos personajes conducen la narración desde el principio hasta el final, mientras el lenguaje cinematográfico se ve reducido a sus elementos mínimos: primeros planos y contraplanos, además de algún zoom. El lenguaje verbal desempeña aquí prácticamente la misma función que en el teatro: es el medio de caracterización de los personajes, de revelación de los conflictos y de progresión de la trama.

La base del relato es la misma que en la obra teatral: un proceso despiadado de selección de personal, que funciona a la manera de una lucha darwiniana por la supervivencia del más apto. En la película, los personajes son ocho: siete aspirantes (cinco hombres y dos mujeres) y la secretaria del departamento de personal. En la obra, en cambio, eran cuatro (tres hombres y una mujer). Por medio de una serie de pruebas psicológicas, Dekia, una empresa multinacional de origen nórdico, pretende determinar cuál de estos «finalistas» tiene el perfil que mejor encaja con los requisitos necesarios para ocupar un alto puesto ejecutivo. Los participantes tienen que eliminarse entre sí, mientras se creen espiados por cámaras y micrófonos, como si estuvieran atrapados en una suerte de Gran Hermano corporativo.

El argumento original surgió de una noticia periodística, según ha contado Galceran en varias entrevistas: el hallazgo, en la basura, de un conjunto de solicitudes para un puesto de trabajo en una cadena de supermercados, sobre las que estaban escritas las 
impresiones -xenófobas, sexistas, discriminatorias- del entrevistador con respecto a los aspirantes. El nombre de la obra iba a ser Selección natural, lo que subrayaba su concepción darwinista.

Una de las principales diferencias entre la obra teatral y la película es que la primera funciona como una comedia (negra), mientras que la segunda se orienta hacia el thriller psicológico. Así, la película deja de lado los pasajes más inclinados hacia la farsa, como la prueba en la que los participantes reciben cuatro sombreros -una montera de torero, uno de payaso, uno de copa y una mitra de obispo- y deben desempeñar esos papeles, en una suerte de role playing. También se deja de lado en el film el debate sobre la decisión de uno de los personajes de someterse a una operación de cambio de sexo, tema que aparece abordado en tono cómico en la obra original.

El suspenso funciona a partir de la amenaza que se cierne sobre todos los personajes: la eliminación. A diferencia del policial, aquí no está en riesgo la vida de nadie: sin embargo, la tensión funciona porque quedar fuera de la selección de personal supone quedar fuera de la trama («It's over», dice una voz computarizada cuando el destino del personaje está sellado). Quien pierde cada prueba, resulta excluido de la competencia -y de la pantalla-. Sometidos a las normas que impone la corporación, el único poder que tienen los personajes es el de expulsar al otro.

Ambas versiones del texto retoman elementos del género reality show: la trama avanza por medio de la competencia entre los participantes, que se define a partir de sucesivas votaciones para eliminar al menos apto. La confesión también tiene un lugar destacado: por ejemplo, cuando Ricardo (Pablo Echarri) cuenta sobre su pasado como sindicalista, o en la obra teatral, cuando Carlos revela su intención de cambiar de sexo. Además, en línea con el ambiente paranoico que crea la narración, los participantes están convencidos de que hay cámaras y micrófonos escondidos en la sala: el espacio donde se desarrolla la trama sería, según la creencia de los personajes, un panóptico.

El espectador lo corrobora hacia el final de la película, cuando la cámara se traslada a una suerte de sala de vigilancia: vemos entonces una serie de pantallas que registran lo que sucede en todos los espacios de ese piso, incluyendo el baño. En esta secuencia, el espectador sale de la sala de reuniones y observa por primera vez a los personajes como un voyeur: como el «Gran Hermano» que los está evaluando. Descubrimos entonces que 
no hay punto ciego, no hay ángulos muertos: todo es visible para ese poder omnisciente que todo lo ve y todo lo escucha -un poder que es pura audio-visión-.

Piñeyro subraya este efecto al utilizar la pantalla dividida: el espectador puede ver simultáneamente lo que sucede en diferentes espacios, tal como el Gran Hermano que conduce la prueba y observa a los participantes. La autoridad aquí no encarna en ningún personaje de la película: ese espacio está vacante y, sin embargo, el sistema funciona solo. A la vez, las cámaras y los micrófonos aparecen como instrumentos de un dispositivo de control: la película parece cuestionar así no solo cierta lógica mediática trasladada, unos pocos años después de su estreno, desde la televisión hacia las redes sociales-, sino el propio funcionamiento del cine como institución.

\section{El juego de las apariencias}

La película busca un mayor grado de realismo que la obra teatral; esta, en cambio, plantea situaciones más extremas. Para empezar, en el escenario construido por el film no hay buzones en la pared con mensajes de la empresa, sino computadoras. En la obra teatral, un personaje revela abruptamente que cambiará de sexo; otro decide permanecer en el proceso aun cuando se entera de que su madre acaba de morir: todo eso no sucede en la película, donde los personajes se ven obligados a mostrar una mayor sutileza. El film de Piñeyro, además, contextualiza la historia en medio de una marcha contra el Banco Mundial y el FMI que será reprimida por la policía: el afuera tiene aquí una mayor presencia, y le imprime a la narración unas coordenadas espacio-temporales más precisas.

Otra diferencia significativa entre ambos textos es el final. En la versión teatral el desenlace propone un giro inesperado: tres de los cuatro personajes resultan ser impostores, empleados de la empresa que no participaban realmente del proceso de selección; sus nombres son falsos; la oficina no es realmente una sala de reuniones. En definitiva, todo el proceso ha sido una farsa y el único candidato real, Fernando, es desestimado. Al explicarle los motivos por los que no ha sido seleccionado, Mercedes/Nieves apela a una sentencia maquiavélica: «No buscamos un buen hombre que parezca un hijo de puta. Lo que necesitamos es un hijo de puta que parezca un buen hombre». De esta manera, la obra subraya que el mundo corporativo se sostiene sobre 
las apariencias (vale decir, el marketing y los buenos modales): solo triunfa aquel que construye la máscara que los demás quieren ver.

El film también pone el acento en la dialéctica entre realidad y apariencia. Por un lado, aquí también hay un «topo» (un impostor, miembro del departamento de selección de personal), que se descubre cuando queda un tercio de película. Por el otro, las apariencias se ponen en juego por medio de los modales de los personajes: la cordialidad puede disfrazar la máxima crueldad. Es el caso, por ejemplo, de la sonrisa constante de la secretaria, Montse, interpretada por Natalia Verbeke: su simpatía disimula con cinismo la violencia y la manipulación que impone la empresa, cuya cara visible representa este personaje.

El desenlace de la película propone otro tipo de desenmascaramiento: se quiebra el único vínculo que parecía asentarse sobre cierto afecto genuino, el de Carlos y Nieves, dos personajes que comparten una historia previa (y por lo tanto, ajena a la lógica que rige en el proceso de selección). Al final, los dos personajes se traicionan mutuamente, en función de los objetivos que les había asignado la empresa. A diferencia de la obra teatral, en la película sí hay un elegido: Carlos. Su último mérito es haber logrado «quebrar» a Nieves: el derrumbe de ella es el triunfo de él.

De esta manera, lo que en la obra teatral era una gran simulación -todo el proceso resulta ser una farsa-, en la película se ve ratificado como un proceso de selección con un ganador concreto. Los diferentes finales se corresponden con los diversos tonos que predominan en cada texto: en la obra teatral predomina lo cómico, a partir de un planteo más lúdico, mientras que en la película todo adquiere un tono más serio. En el film de Piñeyro, la comedia ha dejado lugar al thriller y la solemnidad: al final, no podemos evitar condenar todo lo que hemos visto.

\section{La construcción de los personajes}

Por la austeridad de su puesta en escena, El método es fundamentalmente una película de actores. Por otra parte, una de las diferencias más notorias entre la obra teatral y la película es que esta cuenta con el doble de personajes. El hecho de tener que presentar a ocho sujetos obliga al guion de Piñeyro y Gil a rozar los estereotipos: hay, entre otros, un «macho ibérico» (Fernando, interpretado por Eduard Fernández), un tímido e 
indeciso (Enrique, a cargo de Ernesto Alterio), un ganador (Carlos, interpretado por Eduardo Noriega), y un argentino arrogante y medio contestatario (Ricardo, interpretado por Pablo Echarri).

A diferencia de lo que sucede en la obra teatral, donde los cuatro personajes comparten el protagonismo, en el film no todos tienen la misma jerarquía. Los protagonistas de la película son aquellos que comparten su nombre con un personaje del hipotexto: Carlos, Nieves, Fernando y Enrique, a quienes se suma Ricardo, el argentino. En cambio, los otros tres -Julio, Ana y Montse-, que no existían en la versión de Galceran, en la película son personajes secundarios.

La multiplicación de los personajes exigió a los guionistas aumentar la cantidad de pruebas que componen el proceso de selección, lo que repercute en una duración de casi dos horas. Pero también derivó en la introducción de otros conflictos. En los diálogos se ponen en juego diferencias ideológicas con motivo de la marcha antiglobalización, recelos generacionales, cuestiones de género y distancias de clase. Ricardo aparece como el más progresista, el que siente mayor empatía hacia la protesta; Enrique, en cambio, es un escéptico («Hay cosas que ni un millón de marchas pueden cambiar»); y Fernando, el más conservador (machista, lector del diario $A B C$, etcétera).

Por otra parte, Fernando y Ana (Adriana Ozores) pertenecen a la generación de los «maduros» (tienen más de 40), y desconfían de la «nueva escuela» (representada por Carlos y Nieves). Uno de los soliloquios más largos de la película, justamente, es el que pronuncia Fernando antes de irse, criticando a los jóvenes. Finalmente, la cuestión de género es introducida cuando Ana es eliminada del proceso e interpela a sus compañeros: «¿Me estáis echando por ser mujer, por haber pasado los cuarenta, o por las dos cosas?».

La película trata estos conflictos -ideológicos, de género, de clase y generacionales- de manera explícita. Por momentos los personajes bajan línea, hablan desde una posición desprovista de matices, pronuncian extensos soliloquios que parecen más destinados al espectador que a los demás personajes: la función de esos parlamentos es eminentemente pedagógica. De esta manera, los personajes son utilizados por el director para encarnar discursos sociales: en vez de funcionar como sujetos de carne y hueso, con matices y con cierta densidad psicológica, son voceros. 


\section{La dialéctica entre interior y exterior}

En la obra de Galceran, la utilización del espacio remite al teatro de Harold Pinter. En particular, a El montaplatos (1957), en la que dos personajes están encerrados en un sótano y su única comunicación con el afuera es un montaplatos, por medio del cual reciben mensajes de su jefe. En El método Grönholm, los personajes también están encerrados en una misma sala, pero en un piso alto en vez de un sótano. Y la comunicación con el afuera -es decir, con una autoridad anónima del departamento de personal que conduce la prueba- se da por medio de un buzón disimulado en una de las paredes de la escenografía. En la película, en cambio, los mensajes del afuera llegan a las computadoras que tienen los candidatos: son esas pantallas las que marcan el ritmo del proceso de selección.

En su estudio sobre adaptaciones cinematográficas, Sánchez Noriega sostiene que las películas basadas en textos teatrales tienden a «airear la obra, multiplicando en lo posible los escenarios, [...] trasladando las acciones a espacios exteriores, condensando los diálogos, incluyendo planos documentales, etcétera» (2000: 73). Nada de esto sucede en El método, donde la mayor parte de la acción sucede en una oficina ubicada en lo alto de un rascacielos de Madrid, sede de Dekia, una corporación internacional de capitales suecos. En esto, la película sigue casi al pie de la letra las indicaciones de la obra teatral, cuyo único decorado es también la sala de reuniones de una empresa (con «mobiliario de calidad», «parquet» $\mathrm{y}$ «paredes forradas de madera» según las pautas fijadas por las didascalias).

Piñeyro ya había construido situaciones de encierro en Plata quemada y en Kamchatka, pero aquí el aislamiento se sostiene durante toda la narración. La película transcurre en las oficinas de la empresa -más precisamente, en una sala de reuniones-, con apenas dos excepciones: las primeras secuencias, que muestran a los personajes en sus casas y camino a la entrevista de trabajo; y la última imagen, que muestra a uno de los personajes en la calle, al final de la jornada. A diferencia de la obra teatral de Galceran, estructurada en un solo acto, en la película de Piñeyro hay algunas elipsis temporales, aunque mínimas: todo transcurre en un día, coincidiendo con una jornada laboral desde la mañana hasta el atardecer. 
El encierro y la altura refuerzan la idea de que la corporación está aislada de la calle; pertenecer a la empresa es formar parte de una burbuja. La realidad de la ciudad, por lo tanto, resulta inaccesible: «Lástima que la calle no se vea desde aquí», plantea Ricardo al intentar vislumbrar lo que sucede abajo, pese a que los vidrios no se pueden abrir. Desde la ventana de la corporación, ubicada en el centro financiero -es decir, el centro de poder- de la ciudad, la única vista posible se reduce a las cúpulas de otros edificios. Esa vista es un privilegio del poder: los rascacielos de las multinacionales son los nuevos monumentos del capitalismo, tal vez el legado arquitectónico más representativo de esta etapa de la historia.

El único contacto que los personajes tienen con la realidad exterior -la manifestación antiglobalización- es a través de los medios de comunicación. La radio informa que «Comenzará en Madrid la cumbre del FMI y el Banco Mundial»; la televisión muestra enfrentamientos entre los manifestantes y la policía, además de los embotellamientos; en los diarios, la cumbre es el principal título de tapa. Las imágenes del afuera llegan por medio de la televisión, mientras una presentadora defiende las ventajas de «un mercado libre y globalizado» y dice que la ciudad se ha vuelto «un infierno». Nada de ese caos parece penetrar en el edificio de la corporación, donde todo se ve aséptico y ordenado. A lo largo de la película, la música ambiental, fría y apacible como en una constante llamada en espera, subraya esa sensación de aparente tranquilidad.

Para los personajes encerrados en el edificio de Dekia, las protestas callejeras y la represión policial quedan reducidas a un fuera de campo sonoro. Cuando los personajes se acercan a la ventana, no ven nada. Pero por un momento la cámara sale fuera y nos los muestra desde el otro lado del vidrio: por primera vez se escucha entonces, nítido, el sonido de la manifestación, que incluye helicópteros, explosiones y sirenas policiales. Si el espectador no supiera que se trata de una manifestación, todo le indicaría que afuera está sucediendo una guerra. Mientras el enfrentamiento entre los manifestantes y la policía se agrava, los protagonistas permanecen indiferentes, resguardados por la seguridad que parece garantizarles el espacio corporativo. La corporación queda asimilada con una suerte de bunker: pase lo que pase afuera, el interior se pretende a salvo. 
En El método, el apocalipsis ha sucedido mientras los personajes se sacaban los ojos entre sí. El plano general del final, con el personaje de Nieves (Najwa Nimri) caminando por la calle, muestra un escenario devastado: basura volcada, escombros, folletos rotos, un auto chocado incendiándose y el sonido de sirenas componen un panorama de destrucción. La imagen de esa calle arrasada por el caos y por la violencia de la represión policial evoca las postales del estallido de 2001 en Buenos Aires. Paradójicamente, la destrucción también opera como un signo de esperanza: después de explorar las entrañas del sistema, la película parece apostar a que, tarde o temprano, los mecanismos que lo sostienen se derrumbarán.

\section{Alegoría y contexto social}

El cine de Marcelo Piñeyro se asienta sobre un funcionamiento alegórico que sus contemporáneos del Nuevo Cine Argentino han desestimado. En un célebre ensayo, Jameson (1986) proponía leer todos los textos del tercer mundo como alegorías nacionales: el cine de Piñeyro reclama esa lectura, según la cual las producciones culturales de los ahora llamados países emergentes estarían siempre atravesadas por un imperativo de politización. De esta manera, las películas de Piñeyro trazan una continuidad con el cine argentino de los 80 , en el que la alegoría funcionaba como el principal mecanismo de alusión al contexto social.

Aguilar (2010) entiende que el rechazo a la alegoría y a la pedagogía marcan la diferencia fundamental entre el NCA y el cine de la década de 1980, pero también la frontera entre el «nuevo» cine y aquel que, pese a ser contemporáneo en términos cronológicos, sigue recurriendo a esos «viejos» mecanismos de significación: Piñeyro puede inscribirse en este grupo, junto con directores como Carlos Sorín y Eduardo Mignona.

En El método, el proceso de selección de personal funciona como una clara alegoría del individualismo que constituye el fundamento -y el motor- de las sociedades contemporáneas bajo el sistema económico neoliberal. En las obras de Galceran y Piñeyro, los personajes están librados a su suerte y cada prueba que atraviesan funciona como un round que ilustra el apotegma hobbesiano: homo homini lupus. 
El proceso de selección condensa el modo de funcionamiento corporativo, que a su vez constituye una metonimia del sistema económico: según esta lógica, no hay comunidad ni fraternidad posible; el otro no es más que un enemigo. La máxima virtud en este espacio es la flexibilidad, entendida como la capacidad individual de adecuarse a las reglas impuestas por el poder. Ser flexible significa aquí obedecer unas normas arbitrarias, no institucionalizadas ni consensuadas, sin preguntarse por su sentido.

Tanto la pieza teatral como la película trazan un escenario en el que el único lazo social que une a los personajes es la competencia individual. Es un diagnóstico similar al que propone Bauman, para quien las sociedades contemporáneas se definen por un auge del individualismo y de la responsabilidad individual como consecuencia de «la desregulación, la privatización, la individualización y la conquista y anexión de lo público por parte de lo privado» (2010: 47), tendencias que han derivado en un triunfo del «principio de placer» (individual) sobre el «principio de realidad» (social).

Este sistema atravesó una aguda crisis en la Argentina en diciembre de 2001, tras una década en la que el retroceso del Estado de bienestar y sus políticas universalistas de protección social dieron lugar a un proceso de individualización signado por la «gestión individual del riesgo» (Pereyra, 2013: 55). El año 2001 marcó en la Argentina el fin de la década neoliberal, iniciada con el gobierno de Carlos Menem (1989-1999) y concluida con la caída de Fernando de la Rúa (2000-2001), en un contexto de recesión, desempleo, desindustrialización y estallido social.

Filmada en 2005, El método funciona como una alegoría de ese sistema en el que los procesos de retroceso del Estado, flexibilización y desregulación dejan lugar al gobierno del mercado y el consecuente «sálvese quien pueda». A la vez, parece anticipar la crisis que llegaría a España unos años después, a partir de 2008, de la que varias corporaciones salieron más fortalecidas que nunca: si la palabra emblemática de la crisis argentina fue corralito, la de la crisis española probablemente fue rescate. En ese sentido, la crisis de 2001 ha sido interpretada como una anticipación de la crisis financiera «global» desatada en 2008 en Estados Unidos y los países del sur de Europa (España, Grecia, Portugal) a partir de la crisis de las hipotecas subprime y la caída del banco estadounidense Lehman Brothers. 


\section{Comentarios finales}

El método fue filmada en 2005: entre la crisis argentina y la crisis española, la película pone a sus personajes a competir por un puesto de trabajo en una corporación multinacional, institución que representa de modo emblemático al sistema neoliberal. La empresa es presentada aquí como una burbuja ajena a la realidad exterior; fue precisamente el estallido de una burbuja inmobiliaria lo que dio lugar a la crisis en España en 2008, mientras que la metáfora también ha sido utilizada en la Argentina para aludir a la crisis de 2001, que implicó el fin de la «fiesta menemista» y de la ilusión del «uno a uno».

La película subraya la dimensión alegórica al colocar fuera del edificio, en las calles de la ciudad, una protesta antiglobalización con motivo de una cumbre del FMI y el Banco Mundial. Aunque la cámara prácticamente no sale al espacio exterior, ese espacio parece estar anticipando el futuro -un futuro pasado, como diciembre de 2001 en la Argentina, o próximo, como el 15-M madrileño y los indignados de 2011- para el sistema que impera puertas adentro del edificio, es decir, un sistema regido por la ley del más fuerte.

En El método, todos los personajes resultan equiparados en el juicio que la película parece formular con respecto a ellos. No se busca la identificación del espectador con ninguno de estos sujetos: todos son mostrados como mentirosos o, por lo menos, sospechosos de serlo. La complicidad entre el film y el espectador, en este caso, se fundamenta en el rechazo hacia lo que vemos. La película es explícita en su defensa de la corrección política y, por el trazo grueso de sus posiciones, presupone un receptor con quien no hay disenso posible.

Tal vez esa sea la principal diferencia con la obra teatral, más inclinada a la comedia, menos solemne y más ambigua, en la que incluso uno de los personajes cuestiona «tanta corrección política». Si bien el texto de Galceran también está construido como una alegoría, lo que falta allí es la intención pedagógica que atraviesa el film de Piñeyro.

En definitiva, el funcionamiento alegórico-pedagógico de El método hace que, más allá del suspenso bien logrado, ver la película sea una experiencia tranquilizadora: como espectadores no hacemos más que ratificar nuestra condena hacia la crueldad del mundo corporativo, presentado tal como lo preveíamos. La cuestión invita a repensar la eficacia 
política de los films que, como este, ofrecen planteos sustentados en una posición común con el espectador. ¿Habrá, acaso, buen cine que defienda a las multinacionales?

\section{Referencias bibliográficas}

Aguilar, G. (2010). Otros mundos. Un ensayo sobre el nuevo cine argentino. Buenos Aires: Santiago Arcos.

Bauman, Z. (2010). Mundo consumo. Ética del individuo en la aldea global. Buenos Aires: Paidós.

Bazin, A. (2008). ¿Qué es el cine? Madrid: Rialp.

Bernardes, H.; Lerer, D.; Wolf, S. (Eds.) (2002). El nuevo cine argentino. Temas, autores y estilos de una renovación. Buenos Aires: Tatanka.

Cabal, F. (2009). Dramaturgia española de hoy. Madrid: Ediciones Autor.

Jameson, F. (1986). Third-World Literature in the Era of Multinational Capitalism. Social Text. (15), 65-88.

Perales, L. (2013). Jordi Galcerán: ‘No soy Shakespeare pero sé en qué liga juego' El Cultural, 15/11/2013. [Recuperado en línea] www.elcultural.com/articulo_imp.aspx?id=33627 Consultado el 5 de marzo de 2017

Pereyra, S. (2013). El 2001 como acontecimiento y como proceso. Desestructuración social y crítica de la política. En Pereyra, S.; Vommaro, G. y Pérez, G. (Eds.) La grieta. Política, economía y cultura después de 2001 (pp. 53-65). Buenos Aires: Biblos.

Rubio Alcover, A. (2014). Sin lugar en el mundo. Narrativa, puesta en escena y discurso en las películas hispanoargentinas de Marcelo Piñeyro. Fotocinema. Revista Científica de Cine y Fotografia (8), 133-174.

Sánchez Noriega, J. L. (2000). De la literatura al cine. Teoría y análisis de la adaptación. Barcelona: Paidós. 